Review

\title{
Western Scientific Approaches to Near-Death Experiences
}

\section{Bruce Greyson}

Department of Psychiatry \& Neurobehavioral Sciences, University of Virginia School of Medicine, 210 10th Street NE, Charlottesville, VA 22902-4754, USA; E-Mail: cbg4d@virginia.edu; Tel.: +1-434-924-2281; Fax: +1-434-924-1712

Academic Editors: David San Filippo and Anders Karl Gustaf Gustavsson

Received: 12 October 2015 / Accepted: 4 November 2015 / Published: 9 November 2015

\begin{abstract}
Near-death experiences (NDEs) are vivid experiences that often occur in life-threatening conditions, usually characterized by a transcendent tone and clear perceptions of leaving the body and being in a different spatiotemporal dimension. Such experiences have been reported throughout history in diverse cultures, and are reported today by $10 \%$ to $20 \%$ of people who have come close to death. Although cultural expectations and parameters of the brush with death influence the content of some NDEs, near-death phenomenology is invariant across cultures. That invariance may reflect universal psychological defenses, neurophysiological processes, or actual experience of a transcendent or mystical domain. Research into these alternative explanations has been hampered by the unpredictable occurrence of NDEs. Regardless of the causes or interpretations of NDEs, however, they are consistently associated with profound and long-lasting aftereffects on experiencers, and may have important implications for non-experiencers as well.
\end{abstract}

Keywords: near-death experience; psychological explanation; neurophysiological explanation; mystical experience; science; out-of-body experience; death; attitude change

\section{Introduction}

Near-death experiences (NDEs) are vivid, realistic, subjective experiences that often occur in life-threatening conditions, such as in cardiac or respiratory arrest, head injury, or states of shock. They are usually characterized by a transcendent tone and clear perceptions of having left the physical body and being in a different spatiotemporal dimension of being [1-3]. Prospective studies from several 
different populations have found that NDEs are reported by $10 \%$ to $20 \%$ of people who have come close to death [4-8].

Although the term near-death experience and its acronym NDE were coined by Raymond Moody only 40 years ago [9], accounts of such experiences were known in the folklore and writings of European, Middle Eastern, African, Indian, East Asian, Pacific, and Native American cultures. The first modern collection of such cases was published in 1892 by Albert von St. Gallen Heim [10], and translated into English 80 years later [11]. Stunned by his own near-death experience when he survived a fall in the Alps, Heim collected similar narratives from other mountain climbers, soldiers wounded in war, workers who had fallen from scaffolds, and individuals who had nearly died in accidents and near-drownings.

In coining the term near-death experience, Moody identified 15 commonly reported elements in NDE narratives: ineffability, hearing oneself pronounced dead, feelings of peace and quiet, hearing unusual noises, seeing a dark tunnel, being "out of the body", meeting "spiritual beings", a bright light often experienced as a "being of light", panoramic life review, a realm in which all knowledge exists, cities of light, a realm of bewildered spirits, a "supernatural rescue", sensing an uncrossable border or limit, and returning to the body [9]. Based on a statistical analysis of features reported most frequently by near-death experiencers, Bruce Greyson classified NDE elements into: (a) cognitive features of time distortion, thought acceleration, a life review, and revelation; (b) affective features of peace, joy, cosmic unity, and an encounter with loving "being of light"; (c) seemingly paranormal features of unnaturally vivid sensory experiences, putative extrasensensory experiences and precognitive visions, and out-of-body experiences; and (d) transcendental features of otherworldly encounters with mystical beings, visible spirits, and an uncrossable border to an unearthly realm [12].

The preponderance of research into NDEs suggests that how one comes close to death, or how close one actually comes to death, does not influence the occurrence or type of NDE [13-15]. However, some studies have indicated that physiological details of the close brush with death may play a minor role. For example, NDEs dominated by cognitive features, such as temporal distortions, accelerated thoughts, and a life review, are more common in near-death events that are sudden and unexpected than in those that may have been anticipated [16]. NDEs associated with cardiac arrest resemble out-of-body experiences (OBEs), whereas those without cardiac arrest are more similar to depersonalization, in which one feels oneself or one's body to be unreal; and NDEs occurring to intoxicated persons tend to be bizarre and confused, like hallucinations [17]. Patients in coma due to damage to the brainstem that controls bodily functions are less likely to be peaceful than those in coma due to damage to the cerebral cortex that plays a role in thoughts, perceptions, and memories [18]. Furthermore, individuals who have come closer to death have a higher incidence of NDEs than those who did not $[5,11]$, and are more likely to report certain features, such as an encounter with a brilliant light, enhanced cognitive function, and positive emotions [19]. These differences suggest that the physiological details of the close brush with death play a role in how the NDE is experienced by the individual.

Comparisons of NDE accounts from different cultures suggest that prior beliefs may influence the way a person will report an NDE following a close brush with death. Features such as encountering other beings and realms appear to be nearly universal cross-cultural elements. However, the life review and tunnel sensation are primarily reported in NDEs from Christian and Buddhist cultures and are rare 
among native populations in North America, Australia, and the Pacific islands [20]. These cultural influences had led some scholars a half century ago to interpret NDEs as emotional reactions to the threat of imminent death [21-24]. In recent decades, however, it has become apparent that this variability in reported features reflects not the experience itself but rather the experiencers' ability to process and express an event that is largely ineffable and must be "inevitably cast in the images, concepts and symbols available to the individual" ([25], p. 611).

\section{Proposed Scientific Explanations of Near-Death Experiences}

Most near-death experiencers interpret their NDE as a spiritual experience, and frame their understanding of it in spiritual or religious terms [26]. Religious scholars have examined NDEs in the context of various spiritual faiths, exploring their concordance with particular traditions' teachings regarding death and dying [27]. Although theological approaches can place NDEs in a broader context and are generally consistent with the experiencers' interpretations, they are beyond the scope of this review's focus on Western scientific approaches.

NDEs have proven particularly challenging to explain within a Western scientific paradigm, inasmuch as they involve vivid and complex thinking, perception, and memory formation under conditions in which current neuroscientific models of the mind deem such cognitive processes impossible, such as under general anesthesia and in cardiac arrest [7,8,28]. In recent years, several scientific explanations for NDEs have been proposed, as scientists attempt to understand these profound experiences and integrate them into current neuroscientific models of human cognition. These proposed explanations are based on suggested similarities of NDEs to various psychological or physiological conditions or to speculations regarding psychological or physiological mechanisms thought to be implicated in NDEs.

\subsection{Psychological Explanations}

Because the thoughts, perceptions, and feelings during NDEs are quite different from those in normal states of consciousness, researchers and clinicians have sought to explain NDEs in terms of various psychological states. However, studies of near-death experiencers as a group have found them to be psychologically healthy individuals who do not differ from comparison groups in any measure of mental health [13,14,29-32]. Specifically, near-death experiencers and comparison samples are comparable in intelligence, neuroticism, extraversion, trait and state anxiety, and Rorschach indicators of openness to unusual experience [33]. However, there are some data suggesting that near-death experiencers do differ from comparison groups in some psychological traits. Experiencers tend to be good hypnotic subjects, remember their dreams more often, and are adept at using mental imagery [32,34]. They also tend to acknowledge significantly more childhood trauma and resultant tendencies to feel detached from one's surroundings than do non-experiencers [35]. It is unclear, however, whether these personal traits and recall of prior experiences are aftereffects of NDEs or whether they are differences that preceded the NDEs and may in fact have facilitated them.

Although the preponderance of evidence suggests that near-death experiencers are psychologically healthy, the experience of consciousness during NDEs differs radically from normal perceptions, in that experiencers often report their center of consciousness being separated from the physical body and 
seeing things from a visual perspective outside the body. Furthermore, experiencers often report that their thoughts were dramatically clearer and faster in the NDE and their sensations more vivid, sometimes involving colors and sounds unlike anything experienced under other conditions. Because these phenomena are subjective experiences, they cannot be corroborated by others.

Several psychological hypotheses have been proposed to explain NDEs [36]. For example, it has been proposed that persons faced with potentially inescapable danger attempt to exclude this unpleasant reality from perception and replace it with the pleasurable fantasy of an NDE to protect the individual from being paralyzed by emotional shock [37,38]. Along the lines of that explanation, the expectancy model proposes that NDEs are products of the imagination, constructed from one's personal and cultural expectations to protect against the threat of death. However, although there are some cross-cultural variations in the content of NDEs, individuals often report experiences that conflict with their specific religious and personal expectations regarding death [16,39]. Furthermore, knowledge about NDEs acquired prior to the experience does not influence the reported details of the experience $[13,14,30,40]$. NDEs of people who reported their experiences prior to 1975 , when the term "near-death experience" was coined and the phenomenon first described, did not differ from NDEs reported in more recent years, with the single exception of more frequent descriptions of a tunnel [41].

Another problem for the expectancy model is that children as young as 3 years of age, who may have fewer cultural and religious beliefs about death, report the same characteristic features of NDEs as do adults [29,42-44], and some NDEs have been reported to have occurred during the first year of life, but were described by the child years later $[45,46]$.

NDEs have been interpreted as recollections of the birth experience because they often include a sense of passing through a dark tunnel into a world of light, which was thought to be similar to the experience of being born [47]. However, newborns lack the visual acuity, spatial stability of their visual images, mental alertness, and brain coding capacity to register memories of the birth experience [48]. Furthermore, claims of leaving the body and of passing through a tunnel to another realm are equally common in persons born by cesarean section and those born by normal vaginal delivery, contradicting the prediction of the birth-memory model [49].

It has also been suggested that people with a rich fantasy life, ability to form images in the mind, and tendency to experience sensations intensely are more likely than other people to report NDEs [50]. The actual data regarding such "fantasy proneness" among near-death experiencers have been inconsistent. Some studies have found greater tendencies toward fantasy proneness among near-death experiencers than among comparison groups [34], whereas others have not [35].

NDEs have been compared to a psychological condition called depersonalization, which is a state in which one's thoughts and feelings seem unreal and one loses all sense of identity [24,51]. Both NDEs and depersonalization can involve a sense of detachment from the physical body and distortion of the sense of time. Despite this superficial similarity, however, the two states are quite different, in that depersonalization is experienced as "dreamlike" and unpleasant, whereas NDEs are usually experienced as realistic rather than dreamlike and blissful [29]. Furthermore, the core feature of depersonalization, loss of one's sense of identity, is absent in NDEs [52,53].

NDEs have also been compared to a condition called dissociation, which is a sense of detachment from one's immediate surroundings, including one's own bodily sensations and emotions, often used as a psychological defense mechanisms to ward off anxiety or pain [54]. Some studies have suggested 
that near-death experiencers' tendency to dissociate is higher than that of a comparison sample [35], although still within the range of the normal population $[55,56]$; others have found no differences between near-death experiencers and others [52]. These contradictory findings are consistent with the notion that near-death experiencers are not generally prone to dissociate, but may do so under serious stress [55], as transient dissociation is a common adaptive response to crisis among the general population [57].

Posttraumatic stress disorder (PTSD) is a psychological condition triggered by experiencing or witnessing some trauma and is characterized by recurrent, intrusive thoughts of the traumatic event and by efforts to avoid thinking about it [57,58]. Near-death experiencers, like people with PTSD, report more intrusive memories of their close brush with death than do people who came close to death with no NDEs, but they do not report greater efforts to avoid reminders of that event [59]. Overall, the near-death experiencers' recurrent, intrusive thoughts of the NDE suggest a nonspecific mental cognitive processing of a catastrophic event, but not posttraumatic stress disorder [59].

NDEs have also been compared to autoscopy, which is a visual hallucination of one's body associated with a variety of brain disorders [53]. However, in NDEs, the experiencers view their inactive physical bodies from a visual perspective outside the body, whereas in autoscopy, one's point of perception remains inside the body and one sees a hallucinated duplicate image of the body at some other location [29].

\subsection{Physiological Explanations}

Other researchers have sought explanations for NDEs in terms of normal or abnormal functions of the brain. Several explanatory hypotheses have been proposed linking NDEs to various physiological processes presumed to come into play in a life-threatening situation. Some have suggested that absence of oxygen or decreased oxygen getting to the brain, as a common final pathway to brain death, might be implicated in NDEs. However, decreased oxygen is a highly distressing experience, particularly for those who report perceptual distortions and hallucinations [60]. The distress and agitation typical of decreased oxygen contrast markedly with NDEs, which are usually recalled as peaceful and positive experiences [2,3]. Furthermore, contrary to the hypoxia hypothesis, empirical research on altered oxygen levels has shown that NDEs are associated with increased oxygen levels [7,14], or levels equivalent to those of non-experiencers $[43,61]$, but no study has shown decreased levels of oxygen during NDEs.

A parallel hypothesis attributes NDEs to increased carbon dioxide levels in the brain. However, empirical data on altered carbon dioxide in NDEs have also been inconsistent. Studies have variously reported increased carbon dioxide associated with NDEs [61], decreased carbon dioxide [14], or no change in carbon dioxide levels associated with NDEs [7,43]. The interpretation of these data is unclear, as increased carbon dioxide can be the result of better heart function, which reduces the amnesia usually seen in cardiac arrest. Thus, an association between high carbon dioxide levels and NDE reports, if it existed, might reflect only that patients who can remember more of their cardiac arrest experience in general also report more NDEs. Indeed, amnesia for events of a cardiac arrest is seven times more common in survivors who did not report NDEs than among those who do [8]. 
Some researchers have attributed NDEs to hallucinations produced either by medications given to dying patients, by altered body physiology, or by brain malfunctioning as a person approaches death [62]. However, altered body physiology and brain malfunctions generally produce clouded thinking, irritability, fear, belligerence, and idiosyncratic visions [58], quite unlike the exceptionally clear thinking, peacefulness, calmness, and predictable content generally seen in NDEs [63]. Visions induced by drugs or altered physiology are generally of living persons, whereas those in NDEs are almost always of deceased persons [64]. Moreover, patients who had fevers or were given drugs when near death actually report fewer NDEs and less elaborate experiences than do patients who remain free of drugs and fever $[13,14,64]$. These findings suggest that drugs or physiological alterations in fact inhibit NDEs, or at least interfere with their later recall.

Researchers have proposed several chemical models to explain NDEs, attributing them to a wide variety of substances that transmit impulses from one brain cell to another (neurotransmitters) [65-70]. The number of hypothetical neurotransmitters implicated is quite large, but none of these speculations is supported by any evidence. Likewise, anatomical models have been proposed, identifying the location responsible for NDEs in a wide variety of sites in the brain [65,67,71-77]. Although these models are speculative and none have been tested, any or all of them may suggest pathways through which NDEs may be expressed or interpreted.

Several researchers have compared NDEs to malfunctions in the temporal lobe of the brain, the lobe located behind the temples, because seizures or direct electrical stimulation of that region of the brain can elicit experiences thought to be similar to a sensation of leaving the body [72,78]. However, stimulation of the temporal lobe induces false sensations of bizarre distortions of the body, such as legs changing size or shape [72], which do not occur in NDEs. These bodily illusions induced by brain stimulation occur only with the eyes open and disappear when the eyes are closed, unlike NDEs [79]. Additionally, these "induced out-of-body" illusions are always viewed from the visual perspective of being inside the body, unlike NDEs, and they do not include accurate perceptions of the environment from a spatial perspective distant from the body, as do many NDEs [80,81].

In fact, the vast majority of subjective experiences elicited by stimulation of the temporal lobes are frightening fragments of dreamlike sensations that bear no resemblance to the coherent narratives of NDEs ([82]; [83], pp. 611-55). Furthermore, the vast majority of patients with temporal lobe seizures do not report out-of-body experiences [84]. Studies of near-death experiencers' brain waves have found no clinically significant seizure activity in the temporal lobe [73].

NDEs have also been associated speculatively with intrusion into waking consciousness of thought patterns typical of dream sleep [85]. However, NDEs typically occur under conditions that inhibit dream sleep, such as general anesthesia [86], and dream sleep is actually reduced in near-death experiencers [73].

In the past few years, reports have documented very brief but unexpected increases in brain electrical activity at the point of death [87], or even after cardiac death [88]. However, subjective experiences have not been associated with this electrical activity, so it is not clear whether this brief surge of electricity has any relevance to NDEs. Moreover, the increased electrical activity was not assessed based on standard measures of brain activity but rather on a confidential formula that is known to misinterpret a variety of physiological and environmental signals as brain activity [89,90]. This statistical measure, based on electrical recordings from the patient's forehead, is particular 
vulnerable to false readings coming from electrical activity of the underlying forehead muscle, which even at rest can produce signals that resemble brain waves [91,92].

Recently, it was reported that for 30 seconds after cardiac arrest, rat brains can generate electrical activity that was thought might be related to NDEs [93]. However, this electrical surge was only a tiny fraction of the rat brain's electrical power prior to cardiac arrest and was completely eliminated by anesthesia, which does not eliminate NDEs [94]. Furthermore, this surge in brain electrical activity has not been seen in humans, in whom brain activity decreases and stops within 6-7 seconds of cardiac arrest without any surge [95].

Although many of the neurophysiological mechanisms proposed to explain NDEs are plausible, none has been demonstrated to occur in a near-death state, and some, such as those based on lack of oxygen, have been contradicted by empirical data. No theory has yet been proposed that can account satisfactorily for all the common elements of NDEs. There is no logical reason, however, to demand that one theory explain the entire phenomenon; it may well be that different components of NDEs have different mechanisms.

Several authors have proposed multifactorial models that attribute different NDE features to different mechanisms [62,66,96]. However, these multifactorial models, in an effort to be comprehensive, invoke untestable speculations regarding unspecified chemicals, and in order to explain "all" features of NDEs they ignore key features of the experience that they do not explain, such as accurate out-of-body perceptions [62,97], a problem that one of these authors acknowledged in a broadcast interview [98].

Ultimately, even if evidence were found to support a physiological model for the NDE, that evidence would be open to various interpretations. Correlating a brain state with an experience does not imply that brain states necessarily cause the experience; the brain state may alternatively allow access to or simply reflect the experience. The idea that brain function facilitates but does not cause NDEs has been proposed by some researchers who study physiological correlates of NDEs $[69,76,99]$. As one such researcher expressed it, "understanding how the television set works does not yield any information regarding from where the images and sounds arise" ([100], p. 38).

\subsection{Nonreductionistic Explanations}

The scientific models described above are rooted in the predominant mechanistic-reductionist paradigm that guided Western science in recent centuries. However, it is in the very nature of Western science to test and if necessary modify its axioms and paradigms when they prove inadequate to accommodating the empirical evidence. This is exactly what relativity and quantum physicists did a century ago, sparking a scientific revolution. Physics in the 20th century moved beyond the classical paradigm, which no longer accommodated the predictions and findings of quantum mechanics. Modeled on the success of physics in the past century as it expanded beyond the classical materialist paradigm, neuroscientists in the 21 st century are poised to reconsider their conceptions of the nature of consciousness, particularly in regard to anomalous phenomena like near-death experiences [1].

Several features of NDEs pose serious challenges to the reductionistic model of the mind as a product solely of brain activity. The mental clarity, vivid sensory imagery, and clear memory for the experience are the norm for NDEs that occur under physiological conditions such as deep anesthesia or 
cardiac arrest that, accordingly to current neurophysiological models, should eliminate any consciousness at all [28]. There have been documented and corroborated accurate perceptions by near-death experiencers of incidents that occurred during the time when the brain was fully anesthetized or deprived of any blood flow, as during cardiac or respiratory arrest $[2,3,8]$.

Such phenomena suggest that the brain may function not as the source of our mental activity but rather as a filter or transducer of our thoughts and feelings, much as a radio or television set receives signals from an external source and converts them into a form of energy that we can see and hear [101,102]. Indeed, there is now abundant evidence from phenomena other than NDEs that brain activity facilitates the manifestation of mental activity, while at the same time thoughts and feelings alter both the functioning and the physical structure of the brain [3]. This is not to reject the utility of the reductionistic materialist model of 20th century neuroscience, but rather to recognize that that model may have reached its limits when approaching phenomena like NDEs, just as Newtonian physics reached its limits when approaching subatomic phenomena and extreme velocities [28].

Most near-death experiencers believe that during the NDE some part of them separated from their physical bodies and experienced a glimpse of what postmortem consciousness might be like [28]. Experiencers often report that during the NDEs they viewed their bodies from an out-of-body spatial perspective, sometimes describing accurately what was going on while they appeared to be unconscious [8,14,103-105]. Some of those descriptions may be attributable to guesses about likely events or to retrospective reconstructions based on objects and events glimpsed prior to or after the period of unconsciousness. However, in two extensive controlled studies, some near-death experiencers were able to relate accurate details of idiosyncratic and unexpected events during resuscitations of their hearts, whereas every cardiac arrest survivor in those studies who had not reported an NDE described incorrect equipment and procedures when asked to describe the resuscitation $[14,106]$.

Some people additionally report that, while ostensibly out of the body, they saw events they could not have perceived normally even if they had been conscious, such as events that occurred outside the range of their sense organs $[8,107]$. Various researchers have published cases in which they obtained independent corroboration from physicians and nurses of unconscious patients' accurate out-of-body perceptions during the NDEs, including perceptions of very unlikely objects, such as the plaid shoelaces of a nurse who was present only during the patient's resuscitation and not before or after [108], and a cardiac surgeon "flapping his arms as if trying to fly" during an operation [109]. There are also a few corroborated cases of blind individuals who experienced accurate visual perceptions of objects and events during their NDEs, although NDE accounts among blind individuals are rare and their purported visual perceptions are not always verified by others [110,111]. In a recent review of 93 reports of out-of-body perceptions during NDEs, of which 80 were corroborated by an independent informant, 92\% were completely accurate, $6 \%$ contained some error, and only $1 \%$ was completely erroneous [105].

The accuracy of out-of-body perceptions during NDEs challenges the conception that they are hallucinations. Moreover, individuals who have these veridical out-of-body perceptions usually claim that their mental processes were remarkably clear when they seemed to be separated from their physical bodies, which leads them to believe that they will survive the death of their bodies. However, because near-death experiencers are still alive, their consciousness, even though it may seem to be 
detached from the body, may still remain dependent on the body's survival for its continued existence. Thus, although veridical out-of-body perceptions near death may bear on the relationship between the mind and the body while it is alive, they do not necessarily tell us anything about postmortem conditions [112].

Some near-death experiencers report that, during the time they seemed to be dying, they met deceased relatives and friends. Some of these cases may be hallucinatory reflections of the dying individual's expectations or may represent defensive attempts to reduce fear of impending death by imagining reunion with familiar persons. This explanation is less plausible for children, who have not acquired a concept of death as permanent and who would more naturally hallucinate their living parents or other protectors in times of stress. In fact, however, children virtually never see their living parents in NDEs, and, in some cases, they describe meeting persons, whom they did not know, in sufficient detail to allow their parents to recognize those persons as deceased relatives, or the child may later identify the person from the NDE in a family portrait he or she had never seen before [113].

A type of near-death vision that may provide evidence for postmortem survival is the experience in which persons on their deathbeds see a recently deceased person of whose death they had no knowledge, excluding the possibility that the vision was a hallucination related to the experiencers' expectations [114]. In some of these cases, the experiencer reported meeting a deceased person he or she had never met. For example, a patient during a cardiac arrest had an NDE in which he saw a man he did not know. He later learned from his dying mother that he had been born out of an extramarital affair with a man killed in World War II. Shown a picture of his biological father, he immediately recognized him as the man he had seen during his NDE [115]. In another case, a young girl during heart surgery had an NDE in which she saw a boy who identified himself as her brother, although she thought she was an only child. Her father, moved by her report, confessed that he had had a son she never knew about, who had died before she was born [116]. Although these data are not compelling proof of survival, they cannot be dismissed as hallucinations based on expectation [114].

The difficulty in reconciling NDEs with mainstream neurophysiological models of consciousness has raised questions about the reality of these experiences. Two studies have investigated the quality of memories of NDEs, using a standardized instrument designed to differentiate memories of imagined events from memories of events that actually happened $[117,118]$. In both studies, memories of NDEs were more like memories of real events than like memories of imagined events, and in fact appeared "more real" than the memories of other events that actually happened, making it unlikely that they are products of the imagination. One of these studies also included measurements of brain waves during recall of the NDEs, which contributed further evidence that the memories of NDEs were processed in the brain like memories of real events [118].

\section{Methodological Issues in Scientific Research into NDEs}

Near-death experience accounts have become common in the media in recent years, as many popular books, movies, and television talk shows have fueled the public interest in the topic. Because it is difficult to ascertain the degree to which these accounts have been fabricated or embellished, scientists have generally avoided these accounts and focused instead on unpublicized cases. Although most investigators familiar with the scientific literature on NDE use standardized definitions and 
criteria for NDEs, scientists unfamiliar with this literature have at times used inconsistent definitions. Imprecise definitions have been particularly problematic in studies of brain stimulation, in which strange body image distortions that do not involve visualizing the body from an external perspective are frequently misinterpreted as "out-of-body experiences" [81].

Early research into NDE was limited to collecting anecdotes from experiencers who volunteered their accounts. This likely yielded a sample biased in favor of more verbal and extroverted experiencers who had more elaborate NDEs they deemed worthy of sharing. Later studies involved interviewing all members of a group of individuals likely to have been close to death. Although some of the earlier cohort studies focused on accident victims [10,23,24,119] or survivors of attempted suicide [30,120-124], more recent ones have focused on survivors of cardiac arrest [5-8,14,61,125]. Limiting the sample to cardiac arrest survivors maximizes the possibility that the study participants were indeed close to death, but as noted above, NDEs associated with cardiac arrest may not be typical of NDEs associated with other circumstances.

Research into the etiology of NDEs remains hampered by the difficulty of obtaining direct evidence bearing on the plausible hypotheses, in part because of the unpredictable occurrence of the experience. Psychological hypotheses can be tested indirectly by examining personality traits and cognitive styles of experiencers; but such psychological profiles cannot reveal what defenses, if any, may have operated at the time of the experience. The neurological hypotheses that have been proposed so far are untestable in terms of the current methodological sophistication. Neurophysiological studies may some day bridge the gap between mystical experience and physiological events, but as one neurosurgical team attempting to explain NDEs observed, "there are — at this stage — not even preliminary data on the neurology of the different phenomena associated with NDEs" ([126], p. 320; see also [127]).

Although correlating NDEs with specific brain structures or neurotransmitters would not necessarily tell us what causes NDEs, it would potentially open up new tools and techniques for investigating the mechanisms and aftereffects of these experiences. Although it remains unclear whether direct evidence of postmortem survival is possible, investigation of near-death experiencers' mental functioning during ostensible unconsciousness can provide indirect evidence of the separability of mind and body.

Studies of accurate out-of-body perception reported by near-death experiencers have been limited by the reliance on uncontrolled, retrospective accounts, which may be difficult to verify or assess, due to the possibility of inadvertent sensory cues, subliminal perception, memory distortions, and erroneous probability estimates. The few prospective studies in which visual targets were hidden in places where NDEs might be anticipated failed to provide any evidence of accurate out-of-body perception [128]. A methodological complication of such studies is the questionable motivation for a near-death experiencer to look for and remember an object designated by a researcher as a "target" but having no particular significance for the experiencer.

\section{Implications of Near-Death Experiences}

Regardless of the causes and interpretations of NDEs, they have consistently been shown to have profound and long-lasting effects on experiencers, and may have important implications for non-experiencers as well. 


\subsection{Effects of Near-Death Experiences on the Experiencers}

The personal aftereffects of NDEs are often profound and long-lasting, often dramatically altering the experiencer's attitudes, beliefs, and values, leading to increases in spiritual attitudes and interests, concern for others, appreciation of life, and decreases in fear of death, materialism, and competitiveness [14,129,130]. Near-death experiencers often view themselves as integral parts of a benevolent and purposeful universe in which personal gain, particularly at others' expense, is counterproductive. Studies in several countries have established that these changes are greater in near-death experiencers than in people who survive close brushes with death but do not have NDEs [131-133].

Although Moody described the life-transforming effects of NDEs in his book defining the experience, the first systematic controlled study was published by Russell Noyes five years later. In studies comparing experiencers' attitudes before and after their experiences, Noyes found that they reported a reduced fear of death, a sense of relative invulnerability, a feeling of special importance or destiny, and a strengthened belief in postmortem existence [134]. The same year, Kenneth Ring reported that NDEs led to greater appreciation for life, renewed sense of purpose, greater confidence and flexibility in coping with life's vicissitudes, increased value of love and service and decreased concern with personal status and material possessions, greater compassion for others, heightened sense of spiritual purpose, and a greatly reduced fear of death [13]. Subsequent research comparing cardiac arrest survivors who do and do not report NDEs has consistently shown greater attitude changes in the experiencers, particularly in regard to a sense of sacredness of life and purpose in life [8,125].

Several studies have yielded consistent findings showing changes in the experiencers' perception of self, relationship to others, and attitude toward life [8,13,14,35,125,129-142]. These profound changes in attitudes after NDEs have been corroborated in long-term studies of near-death experiencers. Indeed, survivors of cardiac arrest who reported NDEs reported greater changes 8 years after the event than they had after 2 years [8]. These transformations in attitudes and behavior have also been corroborated by independent surveys with people who had known the experiencers well both before and after the NDE [131].

Changes in perception of the self include loss of a fear of death, strengthened belief in life after death, feeling specially favored by God, a new sense of purpose or mission, and heightened self-esteem [141]. Loss of the fear of death, the most commonly reported effect, is often attributed by experiencers to a new or strengthened belief in postmortem survival and to an experience of death as a joyous reunion. However, despite having less fear of death than other survivors of a near-death event [138], near-death experiencers paradoxically express stronger objections to suicide than do comparison samples, primarily on the basis of increased sense of purpose and self-esteem [122]. The experience in an NDE of an encounter with a loving being is often described as the most meaningful aspect of the NDE, and often forms the basis for a new or enhanced sense of spirituality. A new sense of purpose or mission in life is often related to an experience of having been sent back, or having made a choice to return to life, in order to complete some work. This new sense of purpose contributes to a heightened self-esteem.

Changes in relationship to others include increased compassion and love for others; lessened concern for material gain, recognition, or status; greater desire to serve others; and increased ability to 
express feelings [141]. Compared to other survivors of a close brush with death, near-death experiencers place significantly lower value on social status, professional and material success, and fame [137]. These attitudinal changes may lead to alterations in behavior, including career changes, as experiencers feel less concerned with material gain and success, and reject competition as conflicting with their enhanced sense of compassion. They also report feeling greater understanding, acceptance, and tolerance for others, and become more open and freer in expressing their feelings.

Changed attitudes toward life include greater appreciation of and zest for life, increased focus on the present, deeper religious faith or heightened spirituality, greater search for knowledge, and greater appreciation for nature [141]. Although most people who survive close brushes with death report greater appreciation for life, near-death experiencers manifest this in greater zest for life, more intense appreciation for nature and friendship, and living more fully in the moment without concern for the impression they might make, whereas non-experiencers often respond to a close brush with death by becoming more cautious and less likely to take risks [142]. Many experiencers report a greater sense of spirituality $[131,143,144]$ and report a sense of spiritual transformation $[140,145,146]$.

\subsection{Effects of Near-Death Experiencers on Western Society}

In addition to the well-documented effects of NDEs on the experiencers themselves, there is also evidence that NDEs may profoundly affect non-experiencers. Some of the psychological changes documented in near-death experiencers have been demonstrated in other people who learn of these experiences, as has long been documented in anecdotal reports of the power of knowledge about NDEs to provide comfort, hope, and inspiration to persons who have not themselves had these experiences [147].

Two studies of this effect among college students have corroborated these anecdotal accounts. Sociology students at Miami University of Ohio who had studied NDEs undertook a semester-long project to relate in a compassionate manner to someone they would not have otherwise encountered. Evaluation of the students' personal journals and questionnaires at the end of the semester suggested that the students involved felt increased compassionate concern for others in general and greater feelings of self-worth, findings that were corroborated in a follow-up survey a year after the course ended [129]. In another study, psychology students at the University of Connecticut who had studied NDEs reported at the end of the course greater appreciation of life, more self-acceptance, increased compassionate concern for others, greater spirituality, less interest in materialistic goals, diminished fear of death, and increased belief in the possibility of postmortem survival [35]. In two replications of this study, carried out at the University of Connecticut and at Montana State University, large majorities of the students reported at the end of a course on NDEs a more spiritual orientation toward life, more positive attitudes toward death, decreased concern about dying, and increased sense of purpose in life [147].

Information about NDEs has begun to influence the healthcare profession, as models have been developed for teaching about NDEs in medical and nursing schools [148,149]. In recent years, this information has inspired some changes in practices among healthcare providers as they become more sensitive to the frequency and effects of NDEs on their patients [150]. Information about near-death experiences has been used by therapists and counselors to reduce suicidal thoughts $[123,151,152]$, 
comfort people with terminal illness $[153,154]$ and the bereaved $[151,154]$, and support soldiers going into combat [155].

Within Western society at large, NDEs have become cultural images that are now part of the historical discourse about the ideal society [156]. As they become increasingly disseminated by the popular media, visions of the unearthly world described by near-death experiencers are prompting cultural re-evaluation of personal identity, social values, and lifestyles. Social movements stimulated by rapid and disruptive social changes that had their beginnings in the Industrial Revolution have fragmented and disoriented Western society, which has become a driving force for the recurring pursuit of a morally re-invigorated society. This persistent hope for better world may find added inspiration in near-death experiencers' accounts of the quality of social relationships, the feelings of calm and well-being, and the striking diminution fear of death associated with their experiences [157]. In the context of the cynicism of the past century in Western society, punctuated by two world wars and innumerable domestic and international conflicts and divisions, the increasing cultural interest in NDEs may play a role in rebuilding a shared view of a better society [156].

\section{Conclusions}

Near-death experiences have been reported throughout history in many diverse cultures. Although cultural expectations and parameters of the close brush with death may influence the content of some NDEs, the core near-death phenomenology has not varied through the centuries and around the globe. That invariance may reflect universal psychological defenses, neurophysiological processes, or actual experience of a transcendent or mystical domain. Research into these alternative explanations has been hampered by the spontaneous and unpredictable occurrence of NDEs, and has provided only indirect evidence supporting the psychological, neurophysiological, and transcendent interpretations.

The challenge of complex consciousness, including thought processes, perceptions, and memory formation at a time of severely compromised brain function, suggests the need to expand our models of consciousness and its relation to brain. The prevailing notion that the mind can be reduced to neural processes is a philosophical assumption, and there is nothing inherently unscientific about exploring data challenging that assumption and supporting others. Developments in postclassical physics over the past century offer empirical support for a new scientific conceptualization of the interface between mind and brain [158]. Regardless of the causes or interpretations of NDEs, however, they are consistently associated with profound and long-lasting aftereffects on experiencers, and may have important implications for non-experiencers as well.

\section{Conflicts of Interest}

The author declares no conflict of interest.

\section{References}

1. Enrico Facco, Christian Agrillo, and Bruce Greyson. "Epistemological implications of near-death experiences and other non-ordinary mental expressions: Moving beyond the concept of altered states of consciousness." Medical Hypotheses 85 (2015): 85-93. 
2. Bruce Greyson, Emily W. Kelly, and Edward F. Kelly. "Explanatory models for near-death experiences." In The Handbook of Near-Death Experiences. Edited by Janice Miner Holden, Bruce Greyson and Debbie James. Santa Barbara: Praeger/ABC-CLIO, 2009, pp. 213-34.

3. Emily W. Kelly, Bruce Greyson, and Edward F. Kelly. "Unusual experiences near death and related phenomena." In Irreducible Mind: Toward a Psychology for the 21st Century. Edited by Edward F. Kelly, Emily W. Kelly, Adam Crabtree, Alan Gauld, Michael Grosso and Bruce Greyson. Lanham: Rowman and Littlefield, 2007, pp. 367-421.

4. Bruce Greyson. "The incidence of near-death experiences." Medicine \& Psychiatry 1 (1998): 92-99.

5. Bruce Greyson. "Incidence and correlates of near-death experiences in a cardiac care unit." General Hospital Psychiatry 25 (2003): 269-76.

6. Zalika Klemenc-Ketis, Stefek Grmec, and Janko Kersnik. "Near-death experiences and electrocardiogram patterns in out-of-hospital cardiac arrest survivors." Signa Vitae 6 (2011): 31-35.

7. Sam Parnia, Derek G. Waller, Rebekah Yeates, and Peter Fenwick. "A qualitative and quantitative study of the incidence, features and aetiology of near death experiences in cardiac arrest survivors." Resuscitation 48 (2001): 149-56.

8. Pim van Lommel, Ruud van Wees, Vincent Meyers, and Ingrid Elfferich. "Near-death experience in survivors of cardiac arrest: A prospective study in the Netherlands." Lancet 358 (2001): 2039-45.

9. Raymond A. Moody. Life after Life. Covington: Mockingbird Books, 1975.

10. Albert von St. Gallen Heim. "Notizen über den Tod durch absturz (Remarks on fatal falls)." Jahrbuch der Schweitzerischen Alpenclub 27 (1892): 327-37.

11. Russell Noyes, and Roy Kletti. "The experience of dying from falls." Omega 3 (1972): 45-52.

12. Bruce Greyson. "The Near-Death Experience Scale: Construction, reliability, and validity." Journal of Nervous and Mental Disease 171 (1983): 369-750.

13. Kenneth Ring. Life at Death: A Scientific Investigation of the Near-Death Experience. New York: Coward, McCann \& Geoghegan, 1980.

14. Michael Sabom. Recollections of Death: A Medical Investigation. New York: Harper \& Row, 1982.

15. Vanessa Charland-Verville, Jean-Pierre Jourdan, Marie Thonnard, Didier Ledoux, Anne-Francoise Donneau, Etienne Quartemont, and Steven Laureys. "Near-death experiences in non-life-threatening events and coma of different etiologies." Frontiers in Human Neuroscience 8 (2014): 203.

16. Bruce Greyson. "A typology of near-death experiences." American Journal of Psychiatry 142 (1985): 967-69.

17. Stuart W. Twemlow, Glen O. Gabbard, and Lolafaye Coyne. "A multivariate method for the classification of preexisting near-death conditions." Anabiosis: The Journal of Near-Death Studies 2 (1982): 132-39.

18. Vanessa Charland-Verville, Zulay Lugo, Jean-Pierre Jourdan, Anne-Françoise Donneau, and Steven Laureys. "Near-death experiences in patients with locked-in syndrome: Not always a blissful journey." Consciousness and Cognition 34 (2015): 28-32.

19. Justine E. Owens, Emily W. Cook, and Ian Stevenson. "Features of 'near-death experience' in relation to whether or not patients were near death." Lancet 336 (1990): 1175-77. 
20. Allan Kellehear. "Census of non-western near-death experiences to 2005: Observations and critical reflections." In The Handbook of Near-Death Experiences. Edited by Janice Miner Holden, Bruce Greyson and Debbie James. Santa Barbara: Praeger/ABC-CLIO, 2009, pp. 135-58.

21. Jan Ehrenwald. "Out-of-the-body experiences and the denial of death." Journal of Nervous \& Mental Disease 159 (1974): 227-33.

22. Narcyz Lukianowicz. "Autoscopic phenomena." AMA Archives of Neurology \& Psychiatry 80 (1958): 199-220.

23. Russell Noyes, Paul R. Hoenk, Samuel Kuperman, and Donald J. Slymen. "Depersonalization in accident victims and psychiatric patients.” Journal of Nervous \& Mental Disease 164 (1977): 401-7.

24. Russell Noyes, and Roy Kletti. "Depersonalization in the face of life-threatening danger." Omega 7 (1976): 103-14.

25. Glenn Roberts, and John Owen. "The near-death experience." British Journal of Psychiatry 153 (1988): 607-17.

26. R. David San Filippo. An Overview of the Near-Death Experience Phenomenon. Orlando: Kimball Publishing, 2006.

27. Farnaz Masumian. "World religions and near-death experiences." In The Handbook of Near-Death Experiences. Edited by Janice Miner Holden, Bruce Greyson and Debbie James. Santa Barbara: Praeger/ABC-CLIO, 2009, pp. 159-83.

28. Bruce Greyson. "Implications of near-death experiences for a postmaterialist psychology." Psychology of Religion and Spirituality 2 (2010): 37-45.

29. Glen O. Gabbard, and Stuart W. Twemlow. With the Eyes of the Mind: An Empirical Analysis of Out-of-Body States. New York: Praeger, 1984.

30. Bruce Greyson. "Near-death experiences precipitated by suicide attempt: Lack of influence of psychopathology, religion, and expectations." Journal of Near-Death Studies 9 (1991): 183-88.

31. Janice Miner Holden, Jeffrey Long, and B. Jason MacLurg. "Characteristics of western near-death experiencers." In The Handbook of Near-Death Experiences. Edited by Janice Miner Holden, Bruce Greyson and Debbie James. Santa Barbara: Praeger/ABC-CLIO, 2009, pp. 109-33.

32. Harvey J. Irwin. Flight of Mind: A Psychological Study of the Out-of-Body Experience. Metuchen: Scarecrow Press, 1985.

33. Thomas P. Locke, and Franklin C. Shontz. "Personality correlates of the near-death experiences: A preliminary study." Journal of the American Society for Psychical Research 77 (1983): 311-18.

34. James R. Council, and Bruce Greyson. "Near-death experiences and the 'fantasy-prone' personality: Preliminary findings." Paper presented at the 93rd Annual Convention of the American Psychological Association, Los Angeles, CA, USA, 25 August 1985.

35. Kenneth Ring. The Omega Project: Near-Death Experiences, UFO Encounters, and Mind at Large. New York: Morrow, 1992.

36. Bruce Greyson. "The psychodynamics of near-death experiences." Journal of Nervous \& Mental Disease 171 (1983): 376-81.

37. Oskar Pfister. "Shockdenken und shockphantasien bei höchster todesgefahr (Shock thoughts and fantasies in extreme mortal danger)." Zeitschrift für Psychoanalyse 16 (1930): 430-55.

38. Roy Kletti, and Russell Noyes. "Mental states in mortal danger." Essence 5 (1981): 5-20.

39. Henry Abramovitch. "An Israeli account of a near-death experience: A case study of cultural 
dissonance." Journal of Near-Death Studies 6 (1988): 175-84.

40. Bruce Greyson, and Ian Stevenson. "The phenomenology of near-death experiences." American Journal of Psychiatry 137 (1980): 1193-96.

41. Geena K. Athappilly, Bruce Greyson, and Ian Stevenson. "Do prevailing societal models influence reports of near-death experiences? A comparison of accounts reported before and after 1975." Journal of Nervous \& Mental Disease 194 (2006): 218-22.

42. Nancy Evans Bush. "The near-death experience in children: Shades of the prison-house reopening." Anabiosis: The Journal of Near-Death Studies 3 (1983): 177-93.

43. Melvin L. Morse, Doug Conner, and Donald C. Tyler. "Near-death experiences in a pediatric population: A preliminary report." American Journal of Diseases of Children 139 (1985): 595-600.

44. Melvin L. Morse, Paul Castillo, David Venecia, Jerrold Milstein, and Donald C. Tyler. "Childhood near-death experiences." American Journal of Diseases of Children 140 (1986): 1110-14.

45. David B. Herzog, and John T. Herrin. "Near-death experiences in the very young." Critical Care Medicine 13 (1985): 1074-75.

46. William J. Serdahely, and Barbara A. Walker. "A near-death experience at birth.” Death Studies 14 (1990): 177-83.

47. Carl Sagan. Broca's Brain: Reflections on the Romance of Science. New York: Random House, 1979.

48. Carl B. Becker. "The failure of Saganomics: Why birth models cannot explain near-death phenomena." Anabiosis: The Journal of Near-Death Studies 2 (1982): 102-9.

49. Susan Blackmore. "Birth and the OBE: An unhelpful analogy." Journal of the American Society for Psychical Research 77 (1983): 229-38.

50. Sheryl C. Wilson, and Theodore X. Barber. "The fantasy-prone personality." In Imagery: Current Theory, Research and Application. Edited by Anees A. Sheik. New York: Wiley, 1983, pp. 340-90.

51. Russell Noyes, and Roy Kletti. "Depersonalization in response to life-threatening danger." Comprehensive Psychiatry 18 (1977): 375-84.

52. Harvey J. Irwin. "The near-death experience as a dissociative phenomenon: An empirical assessment." Journal of Near-Death Studies 12 (1993): 95-103.

53. Etzel Cardeña, and Carlos S. Alvarado. "Anomalous self and identity experiences." In The Varieties of Anomalous Experience: Examining the Scientific Evidence, 2nd ed. Edited by Etzel Cardeña, Steven J. Lynn and Stanley Krippner. Washington: American Psychological Association, 2014, pp. 175-212.

54. Etzel Cardeña. "The domain of dissociation.” In Dissociation. Edited by Steven J. Lynn and Judith W. Rhue. New York: Guilford Press, 1994, pp. 15-31.

55. Bruce Greyson. "Dissociation in people who have near-death experiences: Out of their bodies or out of their minds?" Lancet 355 (2000): 460-63.

56. Kenneth Ring, and Christopher J. Rosing. "The Omega Project: An empirical study of the NDE-prone personality.” Journal of Near-Death Studies 8 (1990): 211-39.

57. Etzel Cardeña, and Eve B. Carlson. "Acute stress disorder revisited." Annual Review of Clinical Psychology 7 (2011): 245-67. 
58. American Psychiatric Association. Diagnostic and Statistical Manual of Mental Disorders, 5th ed. Arlington: American Psychiatric Publishing, 2013.

59. Bruce Greyson. "Posttraumatic stress symptoms following near-death experiences." American Journal of Orthopsychiatry 71 (2001): 358-73.

60. William Breitbart, Christopher Gibson, and Annie Tremblay. "The delirium experience: Delirium recall and delirium-related distress in hospitalized patients with cancer, their spouses/caregivers, and their nurses." Psychosomatics 43 (2002): 183-94.

61. Zalika Klemenc-Ketis, Janko Kersnik, and Stefek Grmec. "The effect of carbon dioxide on near-death experiences in out-of-hospital cardiac arrest survivors." Critical Care 14 (2010): R56.

62. Susan Blackmore. Dying to Live: Near-Death Experiences. Buffalo: Prometheus, 1993.

63. Nancy L. Zingrone, and Carlos S. Alvarado. "Pleasurable Western adult near-death experiences." In The Handbook of Near-Death Experiences. Edited by Janice Miner Holden, Bruce Greyson and Debbie James. Santa Barbara: Praeger/ABC-CLIO, 2009, pp. 17-40.

64. Karlis Osis, and Erlendur Haraldsson. At the Hour of Death. New York: Avon, 1977.

65. Daniel B. Carr. "Pathophysiology of stress-induced limbic lobe dysfunction: A hypothesis for NDEs." Anabiosis: The Journal of Near-Death Studies 2 (1982): 75-89.

66. Juan C. Saavedra-Aguilar, and Juan S. Gómez-Jeria. "A neurobiological model for near-death experiences.” Journal of Near-Death Studies 7 (1989): 205-22.

67. Melvin L. Morse, David Venecia, and Jerrold Milstein. "Near-death experiences: A neurophysiological explanatory model." Journal of Near-Death Studies 8 (1989): 45-53.

68. Karl L. R. Jansen. "The ketamine model of the near-death experience: A central role for the $N$-methyl-D-aspartate receptor.” Journal of Near-Death Studies 16 (1997): 5-26.

69. Karl L. R. Jansen. "Response to commentaries on 'The ketamine model of the near-death experience..." Journal of Near-Death Studies 16 (1997): 79-95.

70. Michael A. Persinger. "Near-death experiences: Determining the neuroanatomical pathways by experiential patterns and stimulation in experimental settings." In Le Processus de Guérison: Par-delà Souffrance ou la Mort [Healing: Beyond suffering and death]. Edited by Luc Bessette. Chabanel: Publications MNH, 1994, pp. 277-86.

71. James E. Whinnery. "Psychophysiologic correlates of unconsciousness and near-death experiences." Journal of Near-Death Studies 15 (1997): 231-58.

72. Olaf Blanke, Stephanie Ortigue, Theodor Landis, and Margritta Seeck. "Stimulating illusory own-body perceptions: The part of the brain than can induce out-of-body experiences has been located." Nature 419 (2002): 269-70.

73. Willoughby B. Britton, and Richard R. Bootzin. "Near-death experiences and the temporal lobe." Psychological Science 15 (2004): 254-58.

74. Nina P. Azari, Janpeter Nickel, Gilbert Wunderlich, Michael Niedegger, Harald Hefter, Lutz Tellmann, Hans Herzog, Petra Stoerig, Dieter Birnbacher, and Rudiger J. Seitz. "Neural correlates of religious experience." European Journal of Neuroscience 13 (2001): 1649-52.

75. Peter Fenwick. "The neurophysiology of religious experience." In Psychosis and Spirituality: Consolidating the New Paradigm. Edited by Isabel Clarke. London: Whurr, 2001, pp. 15-26.

76. Jean-Pierre Jourdan. "Near-death and transcendental experiences: Neurophysiological correlates of mystical traditions." Journal of Near-Death Studies 12 (1994): 177-200. 
77. Lawrence C. Wile. "Near-death experiences: A speculative neural model." Journal of Near-Death Studies 12 (1994): 133-42.

78. Olaf Blanke, Theodor Landis, Laurent Spinelli, and Margritta Seeck. "Out-of-body experience and autoscopy of neurological origin." Brain 127 (2004): 243-58.

79. Iris Giesler-Petersen. "Further commentary on 'induced OBEs'." Journal of Near-Death Studies 26 (2008): 306-8.

80. Bruce Greyson, Sam Parnia, and Peter Fenwick. "Visualizing out-of-body experience in the brain.” New England Journal of Medicine 358 (2008): 855-56.

81. Janice Miner Holden, Jeffrey Long, and B. Jason MacLurg. "Out-of-body experiences: All in the brain?" Journal of Near-Death Studies 25 (2006): 99-107.

82. Mardi J. Horowitz, and John E. Adams. "Hallucinations on brain stimulation." In Origin and Mechanisms of Hallucinations. Edited by Wolfram Keup. New York: Plenum, 1970, pp. 13-22.

83. Wilder Penfield, and Phanor Perot. "The brain's record of auditory and visual experience: A final summary and discussion." Brain 86 (1963): 595-696.

84. Orrin Devinsky, Edward Feldmann, Kelly Burrowes, and Edward Bromfield. "Autoscopic phenomena with seizures." Archives of Neurology 46 (1989): 1080-88.

85. Kevin R. Nelson, Michelle Mattingly, Sherman A. Lee, and Frederick A. Schmitt. "Does the arousal system contribute to near-death experience?" Neurology 66 (2006): 1003-9.

86. Bruce Greyson. "Near-death experiences." In The Varieties of Anomalous Experience: Examining the Scientific Evidence, 2nd ed. Edited by Etzel Cardeña, Steven J. Lynn and Stanley Krippner. Washington: American Psychological Association, 2014, pp. 333-67.

87. Lakhmir Chawla, Seth Akst, Christopher Junker, Barbara Jacobs, and Michael G. Seneff. "Surges of electroencephalographic activity at the time of death: A case series." Journal of Palliative Medicine 12 (2009): 1095-100.

88. David B. Auyong, Stephen M. Klein, Tong J. Gan, Anthony M. Roche, DaiWai Olson, and Ashraf S. Habib. "Processed electroencephalogram during donation after cardiac arrest." Anesthesia \& Analgesia 110 (2010): 1428-32.

89. Ashraf A. Dahaba. "Different conditions that could result in the bispectral index indicating an incorrect hypnotic state." Anesthesia \& Analgesia 101 (2005): 765-73.

90. Paul S. Myles, and Sesto Cairo. "Artifact in the bispectral index in a patient with severe ischemic brain injury." Anesthesia \& Analgesia 98 (2004): 706-7.

91. Irina I. Goncharova, Dennis J. McFarland, Theresa M. Vaughan, and Jonathan R. Wolpaw. "EMG contamination of EEG: Spectral and topographical characteristics." Clinical Neurophysiology 114 (2003): 1580-93.

92. Gizem Yilmaz, Pekcan Ungan, Oğuz Sebik, Paulius Uginčius, and Kemal S. Türker. "Interference of tonic muscle activity on the EEG: A single motor unit study." Frontiers in Human Neuroscience 8 (2014): 504.

93. Jimo Borjigin, UnCheol Lee, Tiecheng Liu, Dinesh Pal, Sean Huff, Daniel Klarr, Jennifer Sloboda, Jason Hernandez, Michael M. Wang, and George A. Mashour. "Surge of neuroelectrical coherence and connectivity in the dying brain." Proceedings of the National Academy of Sciences 110 (2013): 14432-37. 
94. Bruce Greyson, Edward F. Kelly, and W. J. Ross Dunseath. "Surge of neurophysiological activity in the dying brain." Proceedings of the National Academy of the Sciences 110 (2013): E4405.

95. Pim van Lommel. "Near-death experiences: The experience of the self as real and not as an illusion." Annals of the New York Academy of Sciences 1234 (2011): 19-28.

96. Dean Mobbs, and Caroline Watt. "There is nothing paranormal about near-death experiences: How neuroscience can explain seeing bright lights, meeting the dead, or being convinced you are one of them." Trends in Cognitive Sciences 15 (2011): 447-49.

97. Bruce Greyson, Janice Miner Holden, and Pim van Lommel. "There is nothing paranormal about near-death experiences' revisited: Comment on Mobbs and Watt." Trends in Cognitive Sciences 16 (2012): 445.

98. Skeptico (Science at the Tipping Point). "Dr. Caroline Watt Defends, There Is Nothing Paranormal About Near-Death Experiences.” Available online: http://bit.ly/MITeGP (accessed on 6 October 2015).

99. Michael A. Persinger. "Modern neuroscience and near-death experiences: Expectancies and implications. Comments on 'A neurobiological model for near-death experiences'." Journal of Near-Death Studies 7 (1989): 233-39.

100. Rick Strassman. “Endogenous ketamine-like compounds and the NDE: If so, so what?" Journal of Near-Death Studies 16 (1997): 27-41.

101. Michael Grosso. "The 'transmission' model of mind and body: A brief history." In Beyond Physicalism: Toward Reconciliation of Science and Spirituality. Edited by Edward F. Kelly, Adam Crabtree and Paul Marshall. Lanham: Rowman \& Littlefield, 2015, pp. 79-113.

102. Edward F. Kelly, and David E. Presti. "A psychobiological perspective on 'transmission' models." In Beyond Physicalism: Toward Reconciliation of Science and Spirituality. Edited by Edward F. Kelly, Adam Crabtree and Paul Marshall. Lanham: Rowman \& Littlefield, 2015, pp. 115-55.

103. Raymond A. Moody. Reflections on Life after Life. St. Simon's Island: Mockingbird Books, 1977.

104. Johann Christoph Hampe. To Die Is Gain: The Experience of One's Own Death. Atlanta: John Knox, 1979.

105. Janice Miner Holden. "Veridical perception in near-death experiences." In The Handbook of Near-Death Experiences. Edited by Janice Miner Holden, Bruce Greyson and Debbie James. Santa Barbara: Praeger/ABC-CLIO, 2009, pp. 185-211.

106. Penny Sartori. The Near-Death Experiences of Hospitalized Intensive Care Patients: A Five-Year Clinical Study. Lewiston: Edward Mellen, 2008.

107. Penny Sartori, Paul Badham, and Peter Fenwick. "A prospectively studied near-death experience with corroborated out-of-body perceptions and unexplained healing." Journal of Near-Death Studies 25 (2006): 69-84.

108. Kenneth Ring, and Madelaine Lawrence. "Further evidence for veridical perception during near-death experiences.” Journal of Near-Death Studies 11 (1993): 223-29.

109. Emily W. Cook, Bruce Greyson, and Ian Stevenson. "Do any near-death experiences provide evidence for the survival of human personality after death? Relevant features and illustrative case reports." Journal of Scientific Exploration 12 (1998): 377-406. 
110. Kenneth Ring, and Sharon Cooper. "Near-death and out-of-body experiences in the blind: A study of apparent eyeless vision.” Journal of Near-Death Studies 16 (1997): 101-47.

111. Kenneth Ring, and Sharon Cooper. Mindsight: Near-Death and Out-of-Body Experiences in the Blind. Palo Alto: William James Center/Institute of Transpersonal Psychology, 1999.

112. Curt J. Ducasse. A Critical Examination of the Belief in a Life after Death. Springfield: Charles C. Thomas, 1961.

113. Paul Badham, and Linda Badham. Immortality or Extinction? Totowa: Barnes \& Noble, 1992.

114. Bruce Greyson. "Seeing dead people not known to have died: 'Peak in Darien' experiences." Anthropology and Humanism 35 (2010): 159-71.

115. Pim van Lommel. "About the continuity of our consciousness." Advances in Experimental Medicine and Biology 550 (2004): 115-32.

116. Elisabeth Kübler-Ross. On Children and Death. New York: Macmillan, 1983.

117. Marie Thonnard, Vanessa Charland-Verville, Serge Brédart, Hedwige Dehon, Didier Ledoux, Steven Laureys, and Audrey Vanhaudenhuyse. "Characteristics of near-death experience memories as compared to real and imagined events memories." PLoS ONE 8 (2013): e57620.

118. Arianna Palmieri, Vincenzo Calvo, Johann R. Kleinbub, Federica Meconi, Matteo Marangoni, Paolo Barilaro, Alice Boggio, Marco Sambin, and Paola Sessa. "'Reality' of near-death experience memories: Evidence from a psychodynamic and electrophysiological integrated study." Frontiers in Human Neuroscience 8 (2014): 429.

119. Russell Noyes, and Donald Slymen. "The subjective response to life-threatening danger." Omega 9 (1978-79): 313-21.

120. Bruce Greyson. "Near-death experiences and attempted suicide." Suicide and Life-Threatening Behavior 11 (1981): 10-16.

121. Bruce Greyson. "Incidence of near-death experiences following attempted suicide." Suicide and Life-Threatening Behavior 16 (1986): 40-45.

122. Bruce Greyson. "Near-death experiences and antisuicidal attitudes." Omega 26 (1992-93): 81-89.

123. Kenneth Ring, and Steven Franklin. "Do suicide survivors report near-death experiences?" Omega 12 (1981-82): 191-208.

124. David H. Rosen. "Suicide survivors: A follow-up study of persons who survived jumping from the Golden Gate and San Francisco-Oakland Bay Bridges." Western Journal of Medicine 122 (1975): 289-94.

125. Janet Schwaninger, Paul R. Eisenberg, Kenneth B. Schechtmann, and Alan N. Weiss. "A prospective analysis of near-death experiences in cardiac arrest patients." Journal of Near-Death Studies 20 (2002): 215-32.

126. Olaf Blanke, and Sebastian Dieguez. "Leaving body and life behind: Out-of-body and near-death experience." In The Neurology of Consciousness. Edited by Steven Laureys and Giulio Tononi. Amsterdam: Academic Press/Elsevier, 2009, pp. 303-25.

127. Enrico Facco, and Christian Agrillo. "Near-death experiences between science and prejudice." Frontiers in Human Neuroscience 6 (2012): 209.

128. Bruce Greyson. "Response to Augustine's 'Does paranormal perception occur in near-death experiences?" Journal of Near-Death Studies 26 (2007): 67-70. 
129. Charles P. Flynn. After the Beyond: Human Transformation and the Near-Death Experience. Englewood Cliffs: Prentice Hall, 1986.

130. Margot Grey. Return From Death: An Exploration of the Near-Death Experience. London: Arkana, 1985.

131. Kenneth Ring. Heading Toward Omega: In Search of the Meaning of the Near-Death Experience. New York: Morrow, 1984.

132. Sutherland. Transformed by the Light: Life After Near-Death Experiences. New York: Bantam Books, 1992.

133. Peter Fenwick, and Elizabeth Fenwick. The Truth in the Light: An Investigation of Over 300 Near-Death Experiences. New York: Berkley Books, 1995.

134. Russell Noyes. "Attitude change following near-death experiences." Psychiatry 43 (1980): 234-42.

135. Charles P. Flynn. "Meanings and implications of NDEr transformations: Some preliminary findings and implications." Anabiosis: The Journal of Near-Death Studies 2 (1982): 3-13.

136. Martin Bauer. "Near-death experiences and attitude change." Anabiosis: The Journal of Near-Death Studies 5 (1985): 39-47.

137. Bruce Greyson. "Near-death experiences and personal values." American Journal of Psychiatry 140 (1983): 618-20.

138. Bruce Greyson. "Reduced death threat in near-death experiencers." Death Studies 16 (1992): 533-46.

139. Gary Groth-Marnat, and Roger Summers. "Altered beliefs, attitudes, and behaviors following near-death experiences.” Journal of Humanistic Psychology 38 (1998): 110-25.

140. Cassandra Musgrave. "The near-death experience: A study of spiritual transformation." Journal of Near-Death Studies 15 (1997): 1878-201.

141. Russell Noyes, Peter Fenwick, Janice Miner Holden, and Sandra Rozan Christian. "Aftereffects of pleasurable Western adult near-death experiences." In The Handbook of Near-Death Experiences. Edited by Janice Miner Holden, Bruce Greyson and Debbie James. Santa Barbara: Praeger/ABC-CLIO, 2009, pp. 41-62.

142. Richard J. Bonenfant. "A comparative study of near-death experience and non-near-death experience outcomes in 56 survivors of clinical death." Journal of Near-Death Studies 22 (2004): 155-78.

143. Steven A. McLaughlin, and H. Newton Malony. "Near-death experiences and religion: A further investigation." Journal of Religion and Health 23 (1984): 149-59.

144. Surbhi Khanna, and Bruce Greyson. "Daily spiritual experiences before and after near-death experiences." Psychology of Religion and Spirituality 6 (2014): 302-9.

145. Bruce Greyson, and Surbhi Khanna. "Spiritual transformation following near-death experiences." Spirituality in Clinical Practice 1 (2014): 43-55.

146. Surbhi Khanna, and Bruce Greyson. "Near-death experiences and spiritual well-being." Journal of Religion and Health 53 (2014): 1605-15.

147. Kenneth Ring. "The impact of near-death experiencers on persons who have not had them: A report of a preliminary study and two replications." Journal of Near-Death Studies 13 (1995): 223-35.

148. Robert D. Sheeler. “Teaching near-death experiences of medical students.” Journal of Near-Death Studies 23 (2005): 239-47. 
149. Mary D. McEvoy. "The near-death experience: Implications for nursing education.” Loss, Grief, and Care 4 (1990): 51-55.

150. Ryan D. Foster, Debbie James, and Janice Miner Holden. "Practical applications of research on near-death experiences." In The Handbook of Near-Death Experiences. Edited by Janice Miner Holden, Bruce Greyson and Debbie James. Santa Barbara: Praeger/ABC-CLIO, 2009, pp. 235-58.

151. John M. McDonagh. "Introducing near-death research findings into psychotherapy." Journal of Near-Death Studies 22 (2004): 269-73.

152. Engelbert J. Winkler. "The Elias Project: Using the near-death experience potential in therapy." Journal of Near-Death Studies 22 (2003): 78-81.

153. Mette Marianne Vinter. "An insight into the afterlife: Informing patients about near-death experiences.” Professional Nurse 10 (1994): 171-73.

154. Bruce J. Horacek. "Amazing grace: The healing effects of near-death experiences on those dying and grieving." Journal of Near-Death Studies 16 (1997): 149-61.

155. Robert M. Sullivan. "Combat-related near-death experiences: A preliminary investigation." Journal of Near-Death Studies 4 (1984): 143-52.

156. Allan Kellehear. "Near-death experiences and the pursuit of the ideal society." Journal of Near-Death Studies 10 (1991): 79-95.

157. Antonia Mills. "Commentary on Allan Kellehear's 'Near-death experiences and the pursuit of the ideal society'." Journal of Near-Death Studies 10 (1991): 113-22.

158. Jeffrey M. Schwartz, Henry P. Stapp, and Mario Beauregard. "Quantum physics in neuroscience and psychology: A neurophysiological model of mind-brain interaction." Physical Transactions of the Royal Society of London, Series B: Biological Sciences 360 (2005): 1309-27.

(C) 2015 by the author; licensee MDPI, Basel, Switzerland. This article is an open access article distributed under the terms and conditions of the Creative Commons Attribution license (http://creativecommons.org/licenses/by/4.0/). 